\title{
O território imperial em questão
}

\section{The imperial territory in question}

\author{
Gabriel Pereira de Oliveira \\ Mestrando, Programa de Pós-graduação em História/Universidade Federal de Minas Gerais. \\ gabrielperoli@gmail.com
}

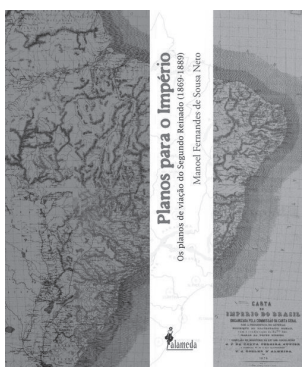

SOUSA NETO, Manoel Fernandes de. Planos para o Império: os planos de viação do Segundo Reinado (1869-1889). São Paulo: Alameda. 2012. $264 p$.
"Tá é tempo de ... deixarmos de ser um povo antigeográfico" (p.189). Com essas palavras, um engenheiro alertava, em 1873, sobre a fragmentação inter-regional que perturbava a ordem no Império de dom Pedro II. A ciência responsável por dar forma ao "corpo" da nação parecia estar longe de ser efetivada. Era preciso criar um espaço que se pudesse dizer nacional, de modo a integrar as mais diversas províncias.

Esse seria um desafio reivindicado especialmente pelos egressos das escolas de engenharia. Eles se colocavam como os mais hábeis para entender os domínios territoriais brasileiros e não hesitaram quanto às soluções - que, logicamente, deveriam caber a eles. As variadas tecnologias de transporte, pautadas em práticas e saberes científicos, foram consideradas primordiais para fomentar a unidade nacional.

Voltado para esse tema da integração espacial no Brasil oitocentista, Planos para o Império: os planos de viação do Segundo Reinado (1869-1889) resulta da tese de doutorado em geografia de Manoel Fernandes de Sousa Neto, defendida em 2004 na Universidade de São Paulo. A publicação somente em 2012 - período de crescentes discussões acerca da questão portuária brasileira que envolveram a aprovação, em 2013, da Medida Provisória dos Portos - ocorreu em momento oportuno para livro, que analisa cinco propostas de sistemas de transporte nacional elaboradas por profissionais da engenharia: os chamados planos de viação.

Embora boa parte dos recentes estudos sobre a temática tenha sido elaborada por engenheiros pautados no teor de descrição técnica e, por vezes, laudatória, Sousa Neto demarca bem sua especificidade como geógrafo e traz contributo singular a esse campo de debates. Seu objetivo é compreender como tais planos estiveram articulados a diferentes projetos políticos de ordenamento geográfico e como foram elaborados com base em determinadas concepções do espaço delimitado como brasileiro.

Ao fazer isso, o autor reforça a perspectiva de historicizar o território, entendendo-o na relação com o tempo. Parte-se da interpretação do elemento espacial não como palco cristalizado das ações humanas, mas como fruto da interação situada historicamente entre 
grupos sociais e seu ambiente - algo desafiador à historiografia. Ao situar seu estudo dentro da chamada geografia histórica, Sousa Neto proporciona uma análise singular do Brasil do Segundo Reinado a partir da constituição do seu território.

O livro transpõe os limites acadêmicos disciplinares e se propõe ao diálogo com outras áreas. É com base em clássicos da historiografia sobre o Oitocentos, como trabalhos de Ilmar Rohloff de Mattos e de José Murilo de Carvalho, que o autor investiga elementos das situações política e econômica que demandavam a integração nacional. Esse aspecto se destacou, sobretudo, após as dificuldades de locomoção enfrentadas pelo exército brasileiro durante a guerra contra o Paraguai.

Do mesmo modo, para compreender o processo de afirmação do saber dos engenheiros, a obra dialoga com estudos acerca da formação e das associações desses profissionais, como os de Vânia Maria Cury e Francisco Foot Hardman. O conhecimento tecnocientífico é percebido em conjunto com suas dimensões sociais específicas.

O contato mais aprofundado com as fontes do período ocorre, principalmente, na análise dos planos. Sousa Neto esmiúça cada uma das propostas de viação, situando os interesses que pautaram os trabalhos dos engenheiros Eduardo José de Moraes (1869), João Ramos de Queiroz (1874; 1882), André Rebouças (1874), Honório Bicalho (1881) e Antônio Bulhões (1882).

Outras obras desses profissionais também são examinadas, para ampliar o entendimento do empenho deles de afirmar determinadas percepções da nação. O cruzamento das fontes, em especial dos planos, explicita muitos acordos e divergências. Percebe-se como se pautavam em concepções específicas do território e em variados projetos políticos.

Na relação entre essas documentações fica claro como os engenheiros formavam grupos e faziam citações uns dos outros, seja para discordar ou para adquirir respaldo científico. Havia elementos em comum, como a própria formação profissional e a participação em associações como o Clube de Engenharia e o Instituto Politécnico.

Exigia-se que as melhorias necessárias ao progresso do país ocorressem de modo "independente das oscilações da política" (p.175). A modernização não poderia permanecer refém de disputas partidárias, seria uma questão relativa apenas ao saber tecnocientífico.

Entre os pontos mais relevantes partilhados estava também o de que os planos analisados fundamentaram seus desenhos em traçados geomorfológicos de bacias hidrográficas. Os referenciais para integrar o território foram, especialmente, os rios Amazonas, Prata e São Francisco. Até o traçado das estradas de ferro foi guiado por cursos d'água. Nesse sentido, Sousa Neto estuda as diferentes leituras que os engenheiros fizeram de mapas como a Carta Corográfica do Império, de 1867, e a Carta Geral do Brasil, de 1875.

A natureza passava a ser o fundamento dos trabalhos de engenharia. Embora fosse considerada dádiva da providência divina, era comum a ideia de que ela necessitaria de aprimoramentos para ser mais bem aproveitada pela sociedade. Sob tal raciocínio, os engenheiros colocavam-se como os mais aptos para pensar os usos do território. Por meio de estudos e relatórios técnicos, demonstravam possuir exímio conhecimento do "mundo natural", proporcionado pela formação em geografia, matemática, física e ciências naturais.

Por outro lado, eram igualmente evidentes as discordâncias em torno de assuntos como o tipo de meio de transporte a ser utilizado. Havia partidários da maior utilização da navegação fluvial, outros, das ferrovias e, inclusive, os que eram favoráveis aos sistemas mistos 
férreo-fluviais. Não obstante, alguns dos mais significativos desacordos entre os autores dos planos de viação surgem nas suas relações com o Estado. Nesses pontos, percebe-se claramente como os trabalhos e as leituras do território feitos por esses "homens de ciência" estavam mesclados a propósitos políticos.

É o caso das querelas relativas às funções do sistema de comunicação. Ao contrário dos demais engenheiros analisados, André Rebouças argumentava a favor da descentralização do poder monárquico. Pautado no federalismo dos Estados Unidos, foi contrário à proposta de que todos os caminhos deveriam levar à sede do poder imperial, como propuseram os adeptos do modelo radial francês - segundo o qual todas as vias de comunicação deveriam dirigir-se a Paris. Um desses, Eduardo José de Moraes, chegou até mesmo a propor a transferência da Corte para o interior, na beira do rio São Francisco, o que ofereceria maior defesa militar e, sobretudo, melhor comunicação com as províncias.

Todos esses são elementos bastante relevantes na obra. Há, todavia, alguns pontos a serem questionados em Planos para o Império. Não está claro, por exemplo, o porquê de a delimitação cronológica ir até 1889 enquanto o cerne da pesquisa está no estudo dos planos situados entre 1869 e 1882.

Caso o argumento seja o de que as propostas dos engenheiros impulsionaram o fim do Império em 1889, deve-se ressaltar a ausência de análises aprofundadas sobre esse aspecto. É difícil perceber, nas fontes analisadas, a noção segundo a qual o Estado se modernizava com o intuito de destituir a monarquia (p.52), ideia que parece associar-se a um viés teleológico. O progresso e a modernidade, afinal, tendiam a estar atrelados à manutenção da ordem e à consolidação do poder imperial, como afirmou o próprio Ilmar Mattos em seus estudos relativos à elite política Saquarema.

O uso de evidências documentais é parco no que diz respeito à conclusão do autor sobre o motivo pelo qual os planos de viação não obtiveram êxito. Com base, especialmente, em referências bibliográficas, Sousa Neto defende que isso ocorreu porque as propostas dos engenheiros favoreceriam a distribuição de terras, sendo, assim, contrárias à lógica da elite agrária de acumular e valorizar suas propriedades fundiárias.

A dimensão do poder dessa elite naquele período poderia ter ficado mais clara, de modo a explicitar se ela possuiria per se a capacidade de barrar os projetos modernizadores. Afinal, algumas das propostas de viação tinham caráter oficial para a instituição monárquica, e muitas delas estavam ligadas a programas de centralização estatal. Além disso, havia pessoas de grande poder econômico apoiando tais obras técnicas e participando ativamente de associações como o Clube de Engenharia.

O exame das disputas entre esses diferentes grupos em torno dos planos deveria ter sido mais aprofundado. Se os meios de transporte estavam intimamente articulados ao crescimento da produção cafeeira - mediante a tríade café-ferrovia-porto -, o autor poderia ter explorado melhor como a elite agrária passou, supostamente, a rejeitar a modernização do sistema de transportes, algo essencial ao escoamento de sua produção.

As propostas de viação tinham claras divergências entre si acerca de pontos cruciais. A distribuição de terras, reivindicada pelo abolicionista André Rebouças, estava longe de ser defendida consensualmente, o que torna difícil concordar com a ideia de que todos os planos seriam igualmente perigosos aos interesses dos senhores de terra e, por isso, rejeitados. 
Embora o autor afirme, em alguns momentos, certa autonomia dos engenheiros para contrapor-se às elites agrárias, seu argumento acerca da não concretização dos planos de viação parece atado à noção de "intelectual orgânico" de Antonio Gramsci. Ao enfatizar os vínculos dessas propostas técnicas com os interesses senhoriais, Sousa Neto confere menor atenção a outros aspectos bastante relevantes.

Além das ambições da elite rural, a falta de sucesso dos planos poderia envolver também as negociações políticas. Era no jogo de disputas parlamentares que se constituía a grande arena onde as bancadas disputavam fervorosamente recursos para melhoramentos nas províncias.

Planos para o Império, apesar disso, evidencia essas questões relativas ao Brasil Imperial, trazendo singular contribuição à historiografia. É uma obra que elucida a articulação entre aparatos técnicos, saberes científicos e o propósito de "refazer" o território nacional com o intuito de torná-lo moderno e integrado em meados do século XIX.

Diante dos crescentes estudos sobre a questão espacial, o livro, portanto, torna-se bastante significativo por mostrar como o território, longe de ser um dado fixo, teve seu caráter disputado por diferentes projetos de nação. Tornar a pátria mais geográfica, como havia sugerido aquele engenheiro em 1873, não foi tarefa simples e óbvia, puro reflexo da superfície natural, mas envolveu o embate entre múltiplas vozes.

Com leitura clara e agradável, a publicação é recomendada, especialmente, àqueles interessados nas relações entre espaço e tempo, como historiadores e geógrafos. Ela pode ser bastante útil também aos estudiosos da articulação entre ciência e tecnologias de transporte elaboradas por engenheiros. 